\title{
Development of a panel of seven duplex real-time PCR assays for detecting 13 streptococcal superantigens
}

\author{
Peng Yang ${ }^{1 \dagger}$, Xiaomin Peng ${ }^{1 \dagger}$, Shujuan $\mathrm{Cui}^{1 \dagger}$, Junbin Shao ${ }^{2}$, Xuping Zhu $^{2}$, Daitao Zhang ${ }^{1}$, Huijie Liang ${ }^{1}$ \\ and Quanyi Wang ${ }^{1 *}$
}

\begin{abstract}
Background: Streptococcal superantigens (SAgs) are the major virulence factors of infection in humans for group A Streptococcus (GAS) bacteria. A panel consisting of seven duplex real-time PCR assays was developed to simultaneously detect 13 streptococcal SAgs and one internal control which may be important in the control of GAS-mediated diseases.

Methods: Primer and probe sequences were selected based on the highly conserved region from an alignment of nucleotide sequences of the 13 streptococcal SAgs. The reaction conditions of the duplex real-time PCR were optimized and the specificity of the duplex assays was evaluated using SAg positive strains. The limit of detection of the duplex assays was determined by using 10-fold serial dilutions of the DNA of 13 streptococcal SAgs and compared to a conventional polymerase chain reaction (PCR) method for evaluating the duplex assays sensitivity.

Results: Using the duplex assays, we were able to differentiate between 13 SAgs from Streptococcus strains and other non-Streptococcus bacteria without cross-reaction. On the other hand, the limit of detection of the duplex assays was at least one or two log dilutions lower than that of the conventional PCR.

Conclusions: The panel was highly specific (100\%) and the limit of detection of these duplex groups was at least ten times lower than that obtained by using a conventional PCR method.
\end{abstract}

Keywords: Streptococcal, Superantigens, Duplex real-time PCR

\section{Background}

Group A Streptococcus (GAS) (Streptococcus pyogenes) is an important gram-positive bacterial pathogen that can cause both invasive and non-invasive infections in humans. GAS-associated diseases are more common in children than in adults $[1,2]$. Among the factors involved in the virulence of the pathogen, the $M$ protein and a group of exotoxins known as streptococcal superantigens (SAgs) have received considerable attention. Streptococcal SAgs are thought to contribute to the pathogenesis of severe GAS infections by virtue of their potent immunos-

\footnotetext{
*Correspondence: bjcdcxm@126.com

${ }^{\dagger}$ Equal contributors

${ }^{1}$ Institute for Infectious Disease and Endemic Disease Control, Beijing Center for Disease Prevention and Control (CDC), Beijing Research Center for Preventive Medicine; Capital Medical University School of Public Health, No.16 He Pingli Middle Street, Dongcheng District, Beijing 100013, China Full list of author information is available at the end of the article
}

timulatory activity [3]. Rapid detection of streptococcal SAgs in clinical samples is therefore important in the efficient control of GAS.

At present, 13 streptococcal SAgs have been identified in GAS to date, including SpeA, SpeC, SpeG, SpeH, SpeI, SpeJ, SpeL, SpeK, SpeM, Ssa, SmeZ and SpeB, SpeF exhibiting the SAg activity [4-7]. 13 conventional polymerase chain reaction (PCR) using 1 primer pair for each SAgs performed in the same volume of reaction mixture and using the standard number of cycles used in previous studies of streptococcal SAgs detection [4]. However, these tests are not suitable for effective, fast, high-throughput routine diagnostic screening because they are labor intensive, the samples are prone to contamination and have relatively lower sensitivity. For large scale detection, a rapid and efficient method for surveillance of streptococcal SAgs in clinical samples is required. 
The aim of this study was to develop a rapid and effective method to simultaneously detect 13 streptococcal SAgs. A panel consisting of seven groups of a duplex real-time PCR assay system described here provides a diagnostic tool for the fast, effective and reliable detection of the 13 currently known streptococcal SAgs.

\section{Materials and methods}

\section{Bacterial strains}

As positive controls, SAgs from Streptococcus MY1, MY3 and FS1 were used in the detection of SpeB, SpeC, SpeF, Spe I and SmeZ, for SpeA, SpeG, SpeJ and Ssa, and for SpeH, SpeK, SpeL and SpeM. Other non-streptococcal bacteria strains including Mycoplasma pneumoniae, Epidemic neisseria meningitides, Streptococcus pneumoniae, Haemophilus influenzae, Staphyloccocus aureus Rosenbach (MRSA), Group B Streptococcus (FT67), Group G Streptococcus (XCN14) were also collected and used in this study.

\section{Primer and probe design}

Primers and probes for the panel of the duplex real-time PCR assays for the detection of 13 streptococcal SAgs were designed targeting the conserved regions of the thirteen streptococcal SAgs gene respectively using Primer Express 3.0 Software (Applied Biosystems, Foster CA). The BLAST program was used to assess and analyse the integrity of the primers and probes (National Center for Biotechnology Information Web site (http:// www.ncbi.nlm.nih.gov/BLAST). These were matched with the conserved gene sequences of 13 corresponding SAgs. The sequence of primers and the probe labeled reporter are listed in Table 1.

\section{Nucleic acid extraction}

Nucleic acid extraction was carried out by mixing $100 \mu \mathrm{l}$ of each sample and $1 \mu \mathrm{l}$ of the internal control followed by the addition of $100 \mu \mathrm{l}$ of nucleic acid extraction solution. This mixture was incubated in boiling water at $100^{\circ} \mathrm{C}$ for $10 \mathrm{~min}$, then centrifuged at 13,000 rpm for $5 \mathrm{~min}$. Five microlitres of the supernatant were removed and used in the detection.

\section{Conventional PCR assay}

The conventional PCR assay was performed using a cycler (Life Express PCR instruments, Yamato, Japan). The PCR reaction and amplification conditions were set up according to the method of Roger Meisa [4]. Briefly, the PCR was carried out in a final volume of $25 \mu \mathrm{l}$. The reaction mixture consisted of $200 \mathrm{nM}$ of each forward and reverse primer, $1 \times$ Enzyme Mix, $400 \mu \mathrm{M}$ of dNTP Mix, $5 \mu \mathrm{l}$ DNA extract and $\mathrm{ddH}_{2} \mathrm{O}$ was used to make up the remaining volume. Amplification was carried out separately for each gene, SpeA to $-C$, SpeF to $-M$, SmeZ, and
Table 1 Duplex real-time PCR primers and probes used in the detection of streptococcal SAgs

\begin{tabular}{|c|c|c|}
\hline Groups & Name & Sequence $\left(5^{\prime}-3^{\prime}\right)$ \\
\hline \multirow[t]{6}{*}{1} & \multirow[t]{3}{*}{ SpeA } & Forward: CAAGAGGTATTTGCTCAACAAG \\
\hline & & Reverse: CACATTCTCGTGAGTAACAGG \\
\hline & & $\begin{array}{l}\text { Probe: FAM-CCCGATCCAAGCCAACTTCACAGA- } \\
\text { BHQ1 }\end{array}$ \\
\hline & \multirow[t]{3}{*}{ Spel } & Forward: GTCAGCACCTTCCTCTTTC \\
\hline & & Reverse: ATCTCCCGTTACCTTCCAG \\
\hline & & Probe: HEX-CGCCTGAGCCGTGAAA-BHQ1 \\
\hline \multirow[t]{6}{*}{2} & \multirow[t]{3}{*}{ SpeB } & Forward: CGGACGTAACTTCTACCATG \\
\hline & & Reverse: TTTGATGCCTACAACAGCAC \\
\hline & & Probe: FAM-AACCGTTGAAGCCGCC-BHQ1 \\
\hline & \multirow[t]{3}{*}{ Ssa } & Forward: CGGGAACTTACCTTCAATTTG \\
\hline & & Reverse: CTATAACTGCTATTATTCGGAAGG \\
\hline & & Probe: HEX-TGCTCAGTAACACCTCC-BHQ1 \\
\hline \multirow[t]{6}{*}{3} & \multirow[t]{3}{*}{ SpeC } & Forward: CGTAACTTTCCAGGAAATTGAC \\
\hline & & Reverse: GCTCATGTTTCCCATCTITTG \\
\hline & & Probe: FAM-CGATTCTGCCGCTTACA-BHQ1 \\
\hline & \multirow[t]{3}{*}{ SpeH } & Forward: AGTTCCTGTAAACGTGTGG \\
\hline & & Reverse: CCTGAGCGGTTACTTTCG \\
\hline & & Probe: HEX-AACAACAGCCGCCTATG-BHQ1 \\
\hline \multirow[t]{6}{*}{4} & \multirow[t]{3}{*}{ SpeG } & Forward: AACAGTTTACTTTACAGGAATTTG \\
\hline & & Reverse: TGTTTACTATCTTIAGTAGCAAGG \\
\hline & & Probe: FAM-AAAGGCTCCCCGATGT-BHQ1 \\
\hline & \multirow[t]{3}{*}{ SpeF } & Forward: CATTGATACCACGACAGCTCTTG \\
\hline & & Reverse: TAGAAGCAAATCGTGATGGCTATC \\
\hline & & $\begin{array}{l}\text { Probe: HEX- } \\
\text { AGCCGCTCCAATCTACAACGCAGACGA-BHQ1 }\end{array}$ \\
\hline \multirow[t]{6}{*}{5} & \multirow[t]{3}{*}{ SpeM } & Forward: TTCGCTATTAACCAACACAGCATC \\
\hline & & Reverse: TGTTATTCCTTGTGTGTGTATCGC \\
\hline & & Probe: FAM-AAGACACTCTCAGTAG-NF-BHQ1 \\
\hline & \multirow[t]{3}{*}{ Spel } & Forward: ATATGATCCAACAGAAGTAAAAGG \\
\hline & & Reverse: CAATCGAACTATTGCCATAAGG \\
\hline & & Probe: HEX-AATGAAGGTCCGCCA-BHQ1 \\
\hline \multirow[t]{6}{*}{6} & \multirow[t]{3}{*}{ Spel } & Forward: TCTACTGGTATGATTTCGTATGCG \\
\hline & & Reverse: TCATGGGTACGGAAGTGTAAAATC \\
\hline & & Probe: FAM-TTGTAGCTTAACGTC-NF-MGB \\
\hline & \multirow[t]{3}{*}{ Smez } & Forward: GCCAATGATTTIAAAGMTGGAG \\
\hline & & Reverse: TATATGCTGTGACTITTCCTTTTG \\
\hline & & Probe: HEX-CTGTGTTCTCCGTCCCA-BHQ1 \\
\hline \multirow[t]{6}{*}{7} & \multirow[t]{3}{*}{ Spek } & Forward: ACGTATCTGAAAAGACACTCTC \\
\hline & & Reverse: ATACCTTGACTTTGTATTCCTTG \\
\hline & & Probe: FAM-AGAGCAAGCGATACACA-BHQ1 \\
\hline & \multirow{3}{*}{$\begin{array}{l}\text { Internal } \\
\text { control }\end{array}$} & Forward: GGTGTATAACGTGTCAGAGACC \\
\hline & & Reverse: CTTCTCCAACATACTATGCAAC \\
\hline & & Probe: HEX-CCTGTCCACCTTCCTC-BHQ1 \\
\hline
\end{tabular}


Table 2 Comparison of the detection limits of a dilution series of DNA (after amplification) using conventional PCR and duplex real-time PCR*

\begin{tabular}{|c|c|c|c|c|c|}
\hline \multirow[t]{2}{*}{ Groups } & \multirow[t]{2}{*}{ Dilution } & \multicolumn{4}{|c|}{ Detection limit } \\
\hline & & $\begin{array}{c}\text { Conventional } \\
\text { PCR }\end{array}$ & $\begin{array}{c}\text { Duplex } \\
\text { real-time } \\
\text { PCR }\end{array}$ & $\begin{array}{c}\text { Conventional } \\
\text { PCR }\end{array}$ & $\begin{array}{c}\text { Duplex } \\
\text { real-time } \\
\text { PCR }\end{array}$ \\
\hline & & \multicolumn{2}{|c|}{ SpeA } & \multicolumn{2}{|l|}{ SpeL } \\
\hline \multirow[t]{6}{*}{1} & $10^{\circ}$ & + & + & + & + \\
\hline & $10^{-1}$ & + & + & + & + \\
\hline & $10^{-2}$ & + & + & + & + \\
\hline & $10^{-3}$ & + & + & - & + \\
\hline & $10^{-4}$ & - & + & - & + \\
\hline & & \multicolumn{2}{|c|}{ SpeB } & \multicolumn{2}{|l|}{ Ssa } \\
\hline \multirow[t]{6}{*}{2} & $10^{\circ}$ & + & + & + & + \\
\hline & $10^{-1}$ & + & + & + & + \\
\hline & $10^{-2}$ & - & + & + & + \\
\hline & $10^{-3}$ & - & + & - & + \\
\hline & $10^{-4}$ & - & - & - & + \\
\hline & & \multicolumn{2}{|c|}{ SpeC } & \multicolumn{2}{|c|}{ SpeH } \\
\hline \multirow[t]{6}{*}{3} & $10^{\circ}$ & + & + & + & + \\
\hline & $10^{-1}$ & + & + & + & + \\
\hline & $10^{-2}$ & + & + & - & + \\
\hline & $10^{-3}$ & - & + & - & + \\
\hline & $10^{-4}$ & - & - & - & - \\
\hline & & \multicolumn{2}{|c|}{ SpeG } & \multicolumn{2}{|c|}{ SpeF } \\
\hline \multirow[t]{6}{*}{4} & $10^{\circ}$ & + & + & + & + \\
\hline & $10^{-1}$ & + & + & + & + \\
\hline & $10^{-2}$ & + & + & + & + \\
\hline & $10^{-3}$ & - & + & - & + \\
\hline & $10^{-4}$ & - & - & - & + \\
\hline & & \multicolumn{2}{|c|}{ SpeM } & \multicolumn{2}{|c|}{ Spel } \\
\hline \multirow[t]{6}{*}{5} & $10^{\circ}$ & + & + & + & + \\
\hline & $10^{-1}$ & + & + & + & + \\
\hline & $10^{-2}$ & + & + & - & + \\
\hline & $10^{-3}$ & - & + & - & + \\
\hline & $10^{-4}$ & - & - & - & - \\
\hline & & \multicolumn{2}{|c|}{ SpeJ } & \multicolumn{2}{|c|}{ SmeZ } \\
\hline \multirow[t]{5}{*}{6} & $10^{\circ}$ & + & + & + & + \\
\hline & $10^{-1}$ & + & + & + & + \\
\hline & $10^{-2}$ & + & + & - & + \\
\hline & $10^{-3}$ & - & + & - & + \\
\hline & $10^{-4}$ & - & + & - & - \\
\hline
\end{tabular}

Table 2 Comparison of the detection limits of a dilution series of DNA (after amplification) using conventional PCR and duplex real-time PCR* (Continued)

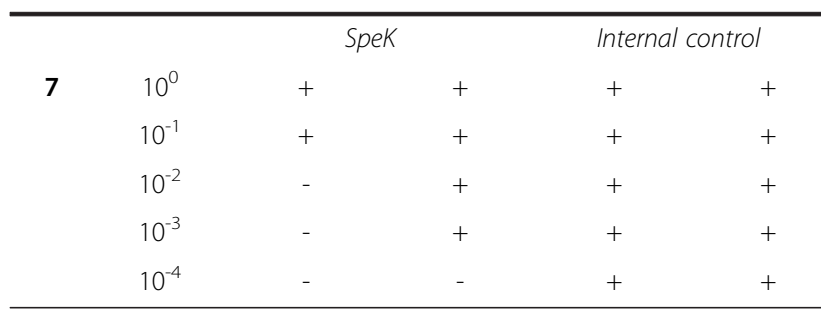

* For each 10-fold DNA dilution, the lowest level of detection of the duplex real-time PCR is shown in addition to the three 10-fold dilutions immediately prior to the lowest limit. Each dilution series was analysed in triplicate to determine relative sensitivity.

Ss $a$, using the respective primers. After an initial denaturation step at $94^{\circ} \mathrm{C}$ for $5 \mathrm{~min}$, amplification was carried out by using 30 cycles at $95^{\circ} \mathrm{C}$ for $40 \mathrm{~s}$, hybridization for $1 \mathrm{~min}$, and elongation at $72^{\circ} \mathrm{C}$ for 1 min $30 \mathrm{~s}$, with annealing at $72^{\circ} \mathrm{C}$ for $5 \mathrm{~min}$. The PCR products were examined using a standardized E-gel electrophoresis system and E-gel 96 with SYBR Safe (Ethrog Biotechnologies, Tel-Hai, Israel).

\section{Duplex real-time PCR assay}

Seven groups of duplex real-time PCR simultaneous amplifications were optimized using the iCycler (Bio-Rad, Hercules, CA,) and the FAM, HEX two channel method using the primers and probes listed in Table 1 . The final optimized $40 \mu \mathrm{l}$ reaction mixture consisted of $200 \mathrm{nM}$ of each forward and reverse primer, $100 \mathrm{nM}$ of TaqMan probe, $1 \times$ Enzyme Mix, $400 \mu \mathrm{M}$ of dNTP Mix, $5 \mu \mathrm{l}$ DNA extract and $\mathrm{ddd}_{2} \mathrm{O}$ was used to make up for the volume. The conditions for the amplification of the seven groups were as follows: $2 \mathrm{~min}$ at $94^{\circ} \mathrm{C}$, followed by 40 cycles of $15 \mathrm{~s}$ at $93^{\circ} \mathrm{C}$ and $60 \mathrm{~s}$ at $55^{\circ} \mathrm{C}$. A C $t$ value between 34 and 36 was considered weakly positive.

\section{Specificity of the duplex real-time PCR assay}

To assess the specificity of the experimental method, the seven groups of duplex real-time PCR reactions were tested for cross-reactivity among the SAgs positive GAS strains and other closely related non-GAS strains, as listed in Materials and Methods. The results were analyzed based on the specific amplification curve either in the FAM or HEX channel depending on the predetermined amplification parameters.

\section{Detection limit of the duplex real-time PCR assay}

To assess the detection limit of the experimental method, DNA templates of 13 streptococcal SAgs were 
serially diluted 10-fold ranging from undiluted to $10^{-4}$. Five different DNA dilutions corresponding to different SAgs were analysed simultaneously using the duplex real-time PCR assay and the conventional PCR assay. The results were analyzed based on the limit of detection the two tests to illustrate the relative sensitivity of each method.

\section{Results}

\section{Specificity of the duplex real-time PCR assay}

To assess the specificity, the Sag positive GAS strains and other closely related non-GAS strains were selected for amplification using the real-time PCR assay. No nonspecific reactions nor any internal cross-amplification was observed (data not shown).

\section{Detection limit of the duplex real-time PCR assay}

To determine the detection limit of the experimental method, the results obtained using the duplex system for the detection of streptococcal SAgs were analyzed and compared to the results obtained from the conventional PCR assay. The DNA was diluted using a 10-fold series ranging from undiluted to $10^{-4}$. The average limit of detection using the duplex system was at least a $10^{-3} \mathrm{di}-$ lution from the undiluted sample and that of the conventional PCR system was at most a $10^{-2}$ dilution. The detection limit of the duplex real-time PCR assays for the detection of SpeA, SpeC, SpeG and SpeM were observed to be lower by one log unit compared with that observed using the conventional PCR assay. The detection limit of the other nine SAgs was observed to be at least two log units lower than that of the conventional PCR assay. The results showing the detection limits of 13 SAgs are listed in Table 2.

\section{Discussion}

To the best of our knowledge, this is the first report of the development of a panel of seven groups of a duplex realtime PCR assay for simultaneously detecting 13 streptococcal SAgs. In the design of these real-time PCRs, an alignment of conserved regions of the target pathogens was made with publicly available GenBank sequences. The primer-probe combination was newly used in the present study and did not cross-react with other similar bacteria strains (data not shown). The specificity of the PCR reactions in these experiments using a novel duplex system was very high $(100 \%)$, and was able to differentiate between different streptococcal SAgs. Furthermore, the detection limit of the duplex real-time PCR was lower by one or two log units than that of the conventional PCR assay. These results indicate that the duplex system described here may be useful in the clinical setting.

There are several advantages of the duplex real-time PCR system compared with the conventional PCR technique, for example, the ease of performance, high specificity and sensitivity, fast turn-around time, a high-throughput capacity, and minimal carry-over contamination [8]. Real-time PCR assays have been widely utilized for early diagnosis of many other bacterial infections [9]. In this study, an internal control was successfully integrated into the assays for accurate interpretation of negative results. The panel of duplex real-time PCR assays could possibly be used as a rapid and efficient diagnostic tool for 13 streptococcal SAgs in the clinical setting.

\section{Conclusions}

The panel of duplex real-time PCR assays described in this report is a simple, specific, sensitive and rapid method for the detection of 13 streptococcal SAgs in clinical samples. This technique has the potential for use in routine diagnostics.

\section{Competing interests}

The authors declare that they have no competing interests.

\section{Authors' contributions}

PY, XP, SC carried out the evaluation experiments, data collection and organization, statistical analysis and contributed to writing and to the interpretation of the results. JS, XZ, DZ and HL carried out the duplex realtime PCR and the sequence alignment. QW contributed to the design of the study and assisted in the drafting of the manuscript. All authors have read and approved the manuscript.

\section{Acknowledgements}

This study was supported by grants from the Beijing Nova Program of the Beijing Science and Technology Commission: (No. 2011047), the National Key Program for Infectious Diseases of China (No. 2012ZX10004215-003-001) and the National Key Program for Infectious Disease of China: (No. 2013ZX10004218).

\section{Author details}

${ }^{1}$ Institute for Infectious Disease and Endemic Disease Control, Beijing Center for Disease Prevention and Control (CDC), Beijing Research Center for Preventive Medicine; Capital Medical University School of Public Health, No.16 He Pingli Middle Street, Dongcheng District, Beijing 100013, China. ${ }^{2}$ Shanghai ZJ Biotech Co. Ltd., No. 188 Xinjunhuan Road, Pujiang High-tech Park Caohejing Development area, Shanghai 201114, China.

Received: 19 March 2013 Accepted: 27 July 2013

Published: 30 July 2013

\section{References}

1. Proft T, Fraser JD: Streptococcal superantigens. Chem Immunol Allergy 2007, 93:1-23.

2. Ma $Y$, Yang $Y$, Huang $M$, Wang $Y$, Chen $Y$, Deng $L, Y u$, Deng $Q$, Zhang $H$, Wang $C$, et al: Characterization of emm types and superantigens of streptococcus pyogenes isolates from children during two sampling periods. Epidemiol Infect 2009, 137:1414-1419.

3. Norrby-Teglund A, Thulin P, Gan BS, Kotb M, McGeer A, Andersson J, Low $D E$ : Evidence for superantigen involvement in severe group $A$ streptococcal tissue infections. J Infect Dis 2000, 184:853-860.

4. Meisal R, Andreasson IK, Høiby EA, Aaberge IS, Michaelsen TE, Caugant DA: streptococcus pyogenes isolates causing severe infections in Norway in 2006 to 2007: emm types, multilocus sequence types, and superantigen profiles. J Clin Microbiol 2010, 48:842-851.

5. Bisno AL, Brito MO, Collins CM: Molecular basis of group A streptococcal virulence. Lancet Infect Dis 2003, 3:191-200. 
6. Cunningham MW: Pathogenesis of group A streptococcal infections. Clin Microbiol Rev 2000, 13:470-511.

7. Proft T, Fraser JD: Bacterial superantigens. Clin Exp Immunol 2003, 133:299-306.

8. Mackay IM, Arden KE, Nitsche A: Real-time PCR in virology. Nucleic Acids Res 2002, 30:1292-1305.

9. Olson $A B$, Sibley $C D$, Schmidt L, Wilcox MA, Surette MG, Corbett CR: Development of real-time PCR assay for detection of streptococcus milleri group for cystic fibrosis clinical specimens by targeting the cpn60 and 16s rRNA genes. J Clin Microbiol 2010, 48:1150-1160.

doi:10.1186/1476-0711-12-18

Cite this article as: Yang et al: Development of a panel of seven duplex real-time PCR assays for detecting 13 streptococcal superantigens. Annals of Clinical Microbiology and Antimicrobials 2013 12:18.

\section{Submit your next manuscript to BioMed Central and take full advantage of:}

- Convenient online submission

- Thorough peer review

- No space constraints or color figure charges

- Immediate publication on acceptance

- Inclusion in PubMed, CAS, Scopus and Google Scholar

- Research which is freely available for redistribution 